\title{
Silencing of the long non-coding RNA GHET1 inhibits cell proliferation and migration of renal cell carcinoma through epithelial-mesenchymal transition
}

\author{
WENJIE XIE $^{1 *}$, XIN LIU $^{2 *}$, QIANG CHEN $^{1}$, MING MA $^{1}$, XIAORONG YANG $^{1}$, \\ BINBIN GONG $^{1}$, TING SUN ${ }^{1}$ and JIE CHEN ${ }^{1}$ \\ ${ }^{1}$ Department of Urology, The First Affiliated Hospital of Nanchang University; ${ }^{2}$ Department of Blood \\ Transfusion, Jiangxi Provincial Children's Hospital, Nanchang, Jiangxi 330000, P.R. China
}

Received April 5, 2018; Accepted December 18, 2018

DOI: $10.3892 / 01.2019 .9967$

\begin{abstract}
Long non-coding RNAs (lncRNAs) have been demonstrated to serve vital roles in renal cell carcinoma (RCC) development. Gastric carcinoma high expressed transcript 1 (GHET1) regulates numerous biological processes in cancer cells. However, the biological role of GHET1 in RCC has not yet been identified. This study aimed to investigate the role of GHET1 in RCC. In the present study, the expression of GHET1 in RCC tissues and the 786-O, A498 and 293 cell lines was assessed by reverse transcription-quantitative polymerase chain reaction. Cell Counting Kit-8, colony formation and cell scratch assays were used to determine the effects of GHET1 on tumorigenesis. Western blotting was performed to examine the effect of GHET1 on epithelial-mesenchymal transition (EMT) in RCC cells. GHET1 expression was significantly increased in the RCC samples in comparison with adjacent tissues. High expression levels of GHET1 were associated with distant metastasis and clinical stage severity, thus, high GHET1 expression may serve as a predictor for a poor prognosis. In addition, RCC cells presented higher GHET1 mRNA and protein expression levels compared with in 293 cells. Furthermore, silencing GHET1 suppressed cell growth, weakened cell migration and inhibited EMT of RCC cells in vitro. In conclusion, the present study suggested that GHET1 may be considered a therapeutic target for the treatment or prevention of RCC.
\end{abstract}

Correspondence to: Dr Jie Chen, Department of Urology, The First Affiliated Hospital of Nanchang University, 17 Yongwai Zhengjie, East Lake, Nanchang, Jiangxi 330000, P.R. China

E-mail: jiechennanchang@163.com

*Contributed equally

Key words: gastric carcinoma proliferation enhancing transcript 1 , IncRNAs, renal cell carcinoma, proliferation, migration, epithelial-mesenchymal transition

\section{Introduction}

In 2018, renal cancers were reported to be among the 10 most common types of cancer in men and women; in addition, 65,340 newly diagnosed cases renal cancer and 14,970 cases of associated mortality are predicted to occur in the United States in 2018 (1). Renal cell carcinoma (RCC) is the most common and lethal among urological cancers, with a mortality rate of $\sim 90 \%$. Localized RCC can be successfully managed with surgery, whereas up to $30 \%$ of patients develop metastasis (2) and $\sim 40 \%$ of patients relapse (3), due to high resistance to conventional chemotherapy. Therefore, the development of effective therapy for RCC is crucial.

Gastric carcinoma high expressed transcript 1 (GHET1) is a long non-coding RNA (lncRNA), which is upregulated in gastric cancer. Non-coding RNAs account for $~ 98 \%$ of the human genome, including microRNAs and a large class of lncRNAs $(4,5)$. Increasing evidence has demonstrated that lncRNAs may serve an important role in the progression of numerous types of carcinoma (6-8). Yang et al demonstrated that high expression levels of GHET1 are correlated with tumor size, tumor invasion and poor survival, and that GHET1 promotes cancer cell proliferation by increasing c-Myc stability and expression (9). Zhou et al confirmed the inhibitory effects of GHET1 on colorectal cancer (10). In this study, authors demonstrated that GHET1 is overexpressed in colorectal cancer, and that GHET1 silencing suppresses cell proliferation, cell cycle arrest, cell migration and cell invasion. GHET1 may therefore represent a novel therapeutic target for the treatment of colorectal cancer. Epithelial-mesenchymal transition (EMT) has been demonstrated to be essential for development and physiological response in carcinogenesis, particularly during the complex initial processes of tissue invasion and extravasation $(11,12)$. Furthermore, EMT is characterized by the loss of epithelial markers, including E-cadherin, and the upregulation of mesenchymal markers, such as Fibronectin and Vimentin (13). However, to the best of our knowledge, the expression and function of GHET1 in RCC remain unknown.

The aim of the present study was to investigate the role of GHET1 in RCC. It was demonstrated that RCC tissues 
and cell lines presented high expression levels of GHET1. In addition, GHET1 knockdown suppressed RCC cell proliferation and migration, thus suggesting that GHET1 may act as an oncogene. The underlying mechanisms of GHET1 in RCC were further investigated.

\section{Materials and methods}

Tissue samples. This study was approved by the Human Ethics Committee of The First Affiliated Hospital of Nanchang University (Nanchang, China). A total of 40 RCC tissues and paired adjacent healthy tissues were obtained from patients undergoing primary RCC resection between April 2010 and August 2015. No chemotherapy was administered to patients prior to sample collection. Clinicopathological characteristics were also collected. All patients provided written informed consent. All samples were identified by histopathological evaluation and stored at $-80^{\circ} \mathrm{C}$. The overall survival (OS) of patients was defined as the time interval between surgery and either mortality or the latest follow-up examination.

Cell culture. The human RCC cell lines 786-O and A498, and 293 cells were obtained from the American Type Culture Collection (Manassas, VA, USA). All cells were cultured in Dulbecco's modified Eagle's medium (DMEM; Gibco; Thermo Fisher Scientific, Inc., Waltham, MA, USA), supplemented with $10 \%$ (v/v) fetal bovine serum (Gibco; Thermo Fisher Scientific), $1 \% 100 \mathrm{U} / \mathrm{ml}$ penicillin and $1 \% 100 \mathrm{mg} / \mathrm{ml}$ streptomycin sulfate (Sigma-Aldrich: Merck KGaA, Darmstadt, Germany) at $37^{\circ} \mathrm{C}$ in a humidified atmosphere containing $5 \%$ $\mathrm{CO}_{2}$.

Cell treatment. Small interfering RNA (siRNA) specifically targeting GHET1 was provided by Shanghai GenePharma Co., Ltd. (Shanghai, China). The interference sequence was 5'-CGGCAGGCATTAGAGATGAACAGCA-3'. A negative control siRNA was purchased from Shanghai GenePharma Co. Ltd. (Cat. No. A06001), which was used as a negative control (NC). Cells were seeded in 6-well plates at 50-70\% confluence and transfected with either the negative control siRNA or GHET1-siRNA (200 nM) using Lipofectamine ${ }^{\circledR}$ 2000 (Invitrogen; Thermo Fisher Scientific, Inc.), according to the manufacturer's protocol. After $48 \mathrm{~h}$ transfection, cells were harvested for subsequent analyses.

Reverse transcription-quantitative polymerase chain reaction (RT-qPCR). Total RNA was isolated from RCC or adjacent tissues, and cells using TRIzol ${ }^{\circledR}$ reagent (Invitrogen; Thermo Fisher Scientific, Inc.). RNA concentration was measured by reading the absorbance at $260 / 280 \mathrm{~nm}$ using a Nanodrop Spectrophotometer (ND-100; NanoDrop; Thermo Fisher Scientific, Inc., Wilmington, DE, USA). cDNA was generated using a PrimeScript ${ }^{\mathrm{TM}}$ RT kit (Invitrogen; Thermo Fisher Scientific, Inc.) according to the manufacturer's protocol. RT-qPCR reactions were performed as follows: $2 \mathrm{~min}$ at $50^{\circ} \mathrm{C}$, $10 \mathrm{~min}$ at $95^{\circ} \mathrm{C}$, followed by 40 cycles at $95^{\circ} \mathrm{C}$ for $15 \mathrm{sec}$ and $1 \mathrm{~min}$ at $60^{\circ} \mathrm{C}$, and an extension step at $72^{\circ} \mathrm{C}$ for $5 \mathrm{~min}$ using the ABI 7500 Real-Time PCR system (Applied Biosystems, Foster City, CA, USA). Each sample was analyzed at least three times. The relative expressions levels were normalized to endogenous controls and were expressed as $2^{-\Delta \Delta C q}(14)$. GHET1 and GAPDH primers were designed as follows: GHET1, forward 5'-TACCACACCCTTTCTTGCCC-3', reverse 5'-GGGAGCCAAAAGGGTCA-3'; and GAPDH, forward 5'-GGGAGCCAAAAGGGTCAT-3' and reverse 5'-GAGTCC TTCCACGATACCAA-3'.

Western blot analysis. Cells were lysed using radioimmunoprecipitation assay buffer (Beyotime Institute of Biotechnology, Shanghai, China) and the protein concentration was measured using Bradford Protein Assay kit (Beyotime Institute of Biotechnology), according to the manufacturer's protocol. Proteins $(50 \mu \mathrm{g})$ were prepared in $1 \mathrm{X}$ sodium dodecyl sulfate buffer, separated by $8-12 \%$ SDS-PAGE and transferred onto polyvinylidene fluoride membranes. The membranes were blocked with 5\% nonfat milk in Tris-buffered saline-Tween

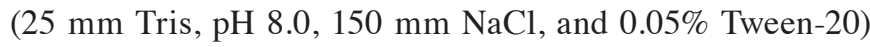
for $2 \mathrm{~h}$ at $37^{\circ} \mathrm{C}$, then incubated with primary antibodies overnight at $4^{\circ} \mathrm{C}$ : E-cadherin (Cat. No. 14472S; 1:1,000; Cell Signaling Technology, Inc., Danvers, MA, USA), Fibronectin (Cat. No. F0916; 1:1,000; Sigma-Aldrich), Vimentin (Cat. No. 49636; 1:1,000, Cell Signaling Technology, Inc.) and GAPDH (Cat. No. 97166; 1:10,000; Cell Signaling Technology, Inc.), and with horseradish peroxidase-conjugated goat anti-mouse immunoglobulin G antibody (Cat. No. 7076; 1:10,000; Cell Signaling Technology) for $1 \mathrm{~h}$ at $37^{\circ} \mathrm{C}$. Enhanced chemiluminescence reagent (Merck KGaA) was used to detect the signal on the membrane. The data were analyzed via densitometry using Image-Pro Plus software 6.0 (Media Cybernetics, Rockville, MD, USA) and normalized to the expression of the internal control ( $\beta$-actin).

Cell Counting Kit-8 (CCK-8) cell proliferation assay. The proliferation of 786-O and A498 cells was assessed using the CCK-8 assay, according to the manufacturer's protocol. Cells in the logarithmic growth phase were seeded into a 96-well culture plate at $3.5 \times 10^{4} /$ well, and at $12 \mathrm{~h}$, the cells were transfected with either the negative control siRNA or the GHET1-siRNA for $12 \mathrm{~h}$. After $0,24,48$ or $72 \mathrm{~h}$ of transfection, $10 \mu$ l CCK- 8 reagents (Dojindo Molecular Technologies, Inc., Kumamoto, Japan) were added to each well, and absorbance was measured at $450 \mathrm{~nm}$ using an enzyme immunoassay analyzer (Bio-Rad Laboratories, Inc., Hercules, CA, USA). Each experiment was repeated at least three times.

Colony formation assay. 786-O and A498 cells (500/well) in the logarithmic growth phase were transfected with the control siRNA or GHET1 siRNA, and were plated in 6-well plates. After 2 weeks, cells were washed twice with phosphate-buffered saline (PBS, Sigma-Aldrich), then fixed with $4 \%$ paraformaldehyde (Sigma-Aldrich) for $15 \mathrm{~min}$ and stained with $0.5 \%$ crystal violet (Sigma-Aldrich) for $20 \mathrm{~min}$ at $37^{\circ} \mathrm{C}$. The number of colonies was calculated by use of ImageJ software V.1.48 (National Institutes of Health, Bethesda, MD, USA). The experiment was performed in triplicate.

Cell migration assay. A total of $1 \times 10^{5} 786-\mathrm{O}$ and A498 cells were transfected with GHET1-siRNA or control siRNA 
A
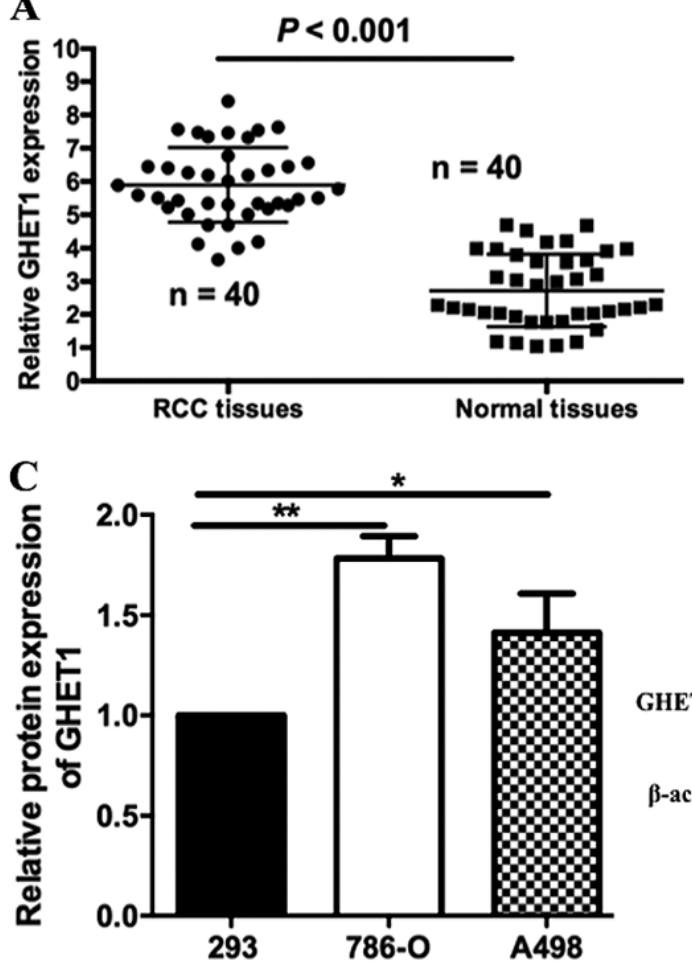
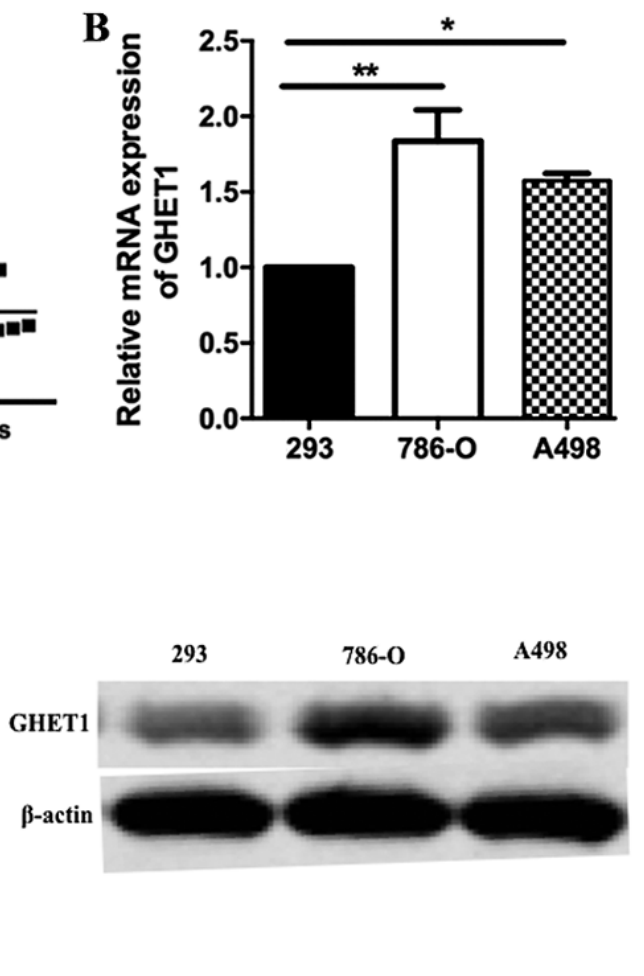

Figure 1. GHET1 is significantly upregulated in RCC tissues and cell lines. (A) Relative expression of GHETI in RCC tissues (n=40) compared with the corresponding normal tissues $(\mathrm{n}=40)$. GHETI expression was assessed by reverse transcription-quantitative polymerase chain reaction and normalized to GAPDH expression. (B) mRNA expression levels of GHETI in two RCC cell lines (786-O and A498) and normal 293 cells. (C) Protein expression levels of GHETI in two RCC cell lines (786-O and A498) and normal 293 cells. Assays were performed in triplicate. ${ }^{*} \mathrm{P}<0.05,{ }^{* * *} \mathrm{P}<0.01$. GHET1, gastric carcinoma proliferation enhancing transcript 1 ; RCC, renal cell carcinoma.

for $6 \mathrm{~h}$, and a scratch was made in the cell monolayer. Cell debris was washed by PBS and cells were incubated at $37^{\circ} \mathrm{C}$ for $48 \mathrm{~h}$. Images of the cells were captured under an inverted microscope (x10 magnification, Leica Microsystems GmbH, Wetzlar, Germany) 0 and $24 \mathrm{~h}$ after scratching.

Statistical analysis. GraphPad Prism 5 software (GraphPad Software, Inc., La Jolla, CA, USA) was used for statistical analysis, and data are presented as the means \pm standard deviation from three independent experiments. All P-values were calculated using unpaired Student's t-test or one-way analysis of variance with Tukey's post hoc test. Paired Student's t-test was applied to analyze the differences of GHET1 expression levels between RCC tissues and adjacent normal tissues. The Pearson's $\chi^{2}$ test was used to determine the difference between GHET1 expression levels and clinicopathological factors. $\mathrm{P}<0.05$ was considered to indicate a statistically significant difference.

\section{Results}

GHET1 is upregulated in RCC tissues and cell lines. In order to investigate the biological function of GHET1 in RCC, the expression levels of GHET1 were assessed in 40 RCC tissues and adjacent normal tissues by RT-qPCR. As illustrated in Fig. 1A, GHET1 expression was significantly increased in the RCC samples compared with the adjacent tissues $(\mathrm{P}<0.001)$. The expression levels of GHET1 in 293, 786-O and A498 cell lines were also measured. When normalized to 293 levels, GHET1 was overexpressed in 786-O and A498 cells (Fig. 1B). Relative protein expression levels of GHET1 were similar, as determined by western blotting (Fig. 1C). These results indicated that GHET1 may act as an oncogene in RCC progression.

Association between GHET1 expression and clinical characteristics in $R C C$. The possible association between the expression levels of GHET1 and the clinicopathological characteristics of patients was then measured. A total of 40 RCC tissues were classified into two groups, based on the median ratio of relative GHET1 expression (6.2), as follows: The high-GHET1 group $(n=29)$ with GHET1 expression ratio $\geq$ median ratio; and the low-GHET1 group $(n=11)$ with GHET1 expression ratiosmedian ratio. As demonstrated in Table I, upregulated GHET1 expression was associated with histological grade, clinical stage and metastasis, but not with age and sex. Notably, a higher number of patients with increased GHET1 expression levels were in the III-IV phases $(\mathrm{P}<0.05)$ or suffered from cancer metastasis $(\mathrm{P}<0.05)$. These results suggested that GHET1 may serve an important role in RCC development.

GHET1-siRNA induces effective silencing of GHET1. To investigate the role of GHET1 in RCC cells, GHET1-siRNA or control siRNA (NC group) plasmids were transfected into 786-O and A498 cells (Fig. 2). After 48 h, the interference efficiency was demonstrated to be significant in the GHET1-siRNA group compared with in the NC group 
Table I. Association between GHET1 expression and clinical characteristics in renal cell carcinoma.

\begin{tabular}{|c|c|c|c|c|c|}
\hline \multirow[b]{2}{*}{ Clinicopathological characteristic } & \multirow[b]{2}{*}{ Number } & \multicolumn{2}{|c|}{$\begin{array}{l}\text { Relative expression of } \\
\text { GHET } 1\end{array}$} & \multirow[b]{2}{*}{$\chi^{2}$} & \multirow[b]{2}{*}{ P-value } \\
\hline & & $\operatorname{High}(n)$ & Low (n) & & \\
\hline Sex & & & & 1.189 & 0.916 \\
\hline Male & 28 & 21 & 7 & & \\
\hline Female & 12 & 8 & 4 & & \\
\hline Age (years) & & & & 1.332 & 0.818 \\
\hline$<60$ & 24 & 15 & 9 & & \\
\hline$\geq 60$ & 16 & 14 & 2 & & \\
\hline Histological grade & & & & 7.122 & $0.035^{\mathrm{a}}$ \\
\hline I-II & 7 & 5 & 2 & & \\
\hline III-IV & 33 & 24 & 9 & & \\
\hline Clinical stage & & & & 8.322 & $0.029^{\mathrm{a}}$ \\
\hline I-II & 10 & 6 & 4 & & \\
\hline III-IV & 30 & 23 & 7 & & \\
\hline Metastasis & & & & 6.977 & $0.034^{\mathrm{a}}$ \\
\hline Yes & 31 & 22 & 9 & & \\
\hline No & 9 & 7 & 2 & & \\
\hline
\end{tabular}

GHET1, gastric carcinoma proliferation enhancing transcript $1 .{ }^{\mathrm{a}} \mathrm{P}<0.05$.
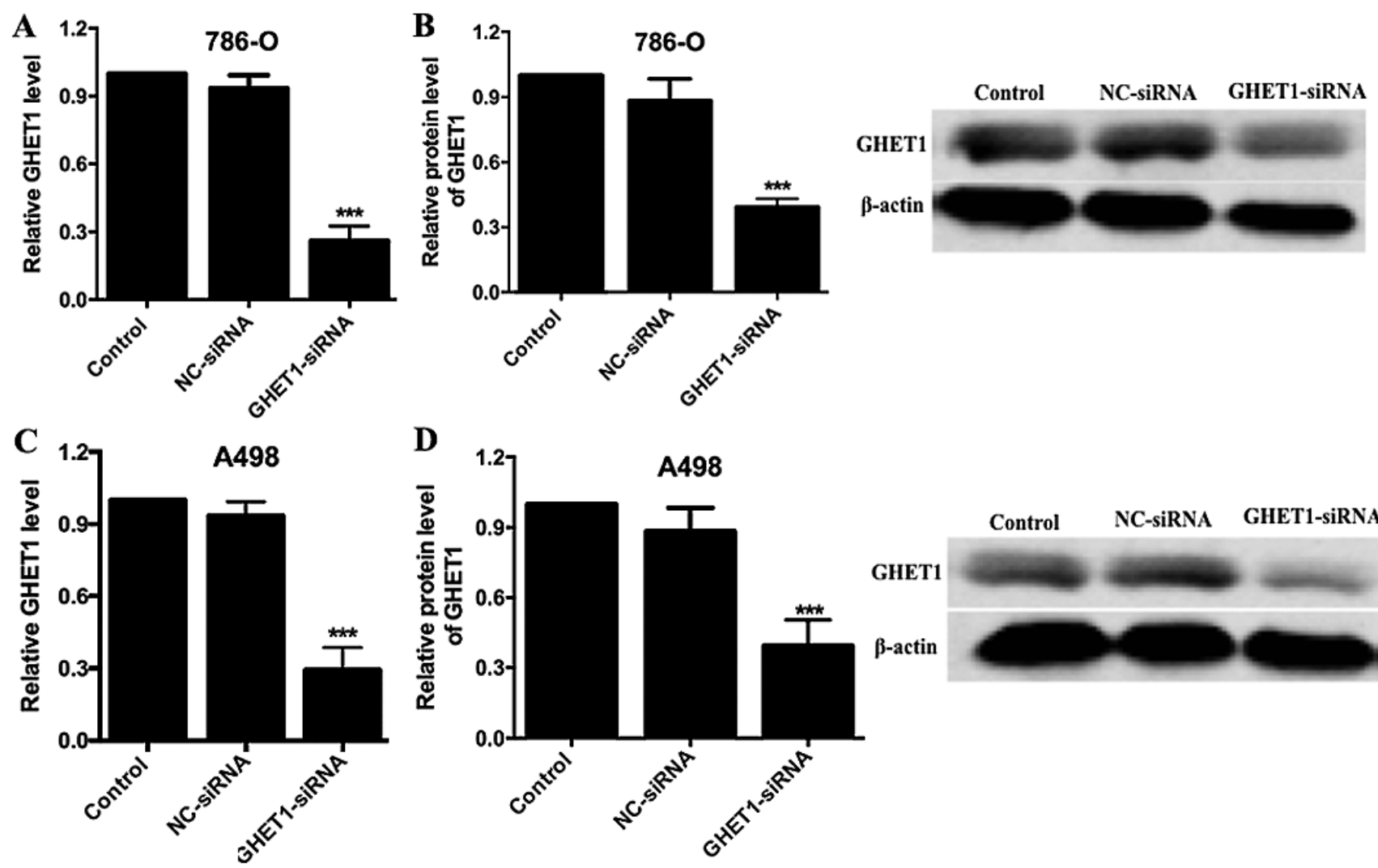

Figure 2. GHET1-siRNA induces effective silencing of GHETl. (A) RT-qPCR demonstrated that the relative expression levels of GHETl were decreased following transfection of 786-O cells with GHETl-siRNA, compared the transfection with NC-siRNA. (B) Western blotting revealed that the relative expression levels of GHETl were decreased following transfection of 786-O cells with GHETl-siRNA, compared with transfection with NC-siRNA. (C) RT-qPCR results demonstrated that the relative expression levels of GHETl were decreased following transfection of A498 cells with GHETl-siRNA, compared with transfection with NC-siRNA. (D) Western blotting revealed that the relative expression levels of GHETl were decreased following transfection of A498 cells with GHET1-siRNA, compared with transfection with NC-siRNA. ${ }^{* * *} \mathrm{P}<0.001$, vs. paired NC group. GHET1, gastric carcinoma proliferation enhancing transcript 1; NC, negative control; RT-qPCR, reverse transcription-quantitative polymerase chain reaction; siRNA, small interfering RNA. 

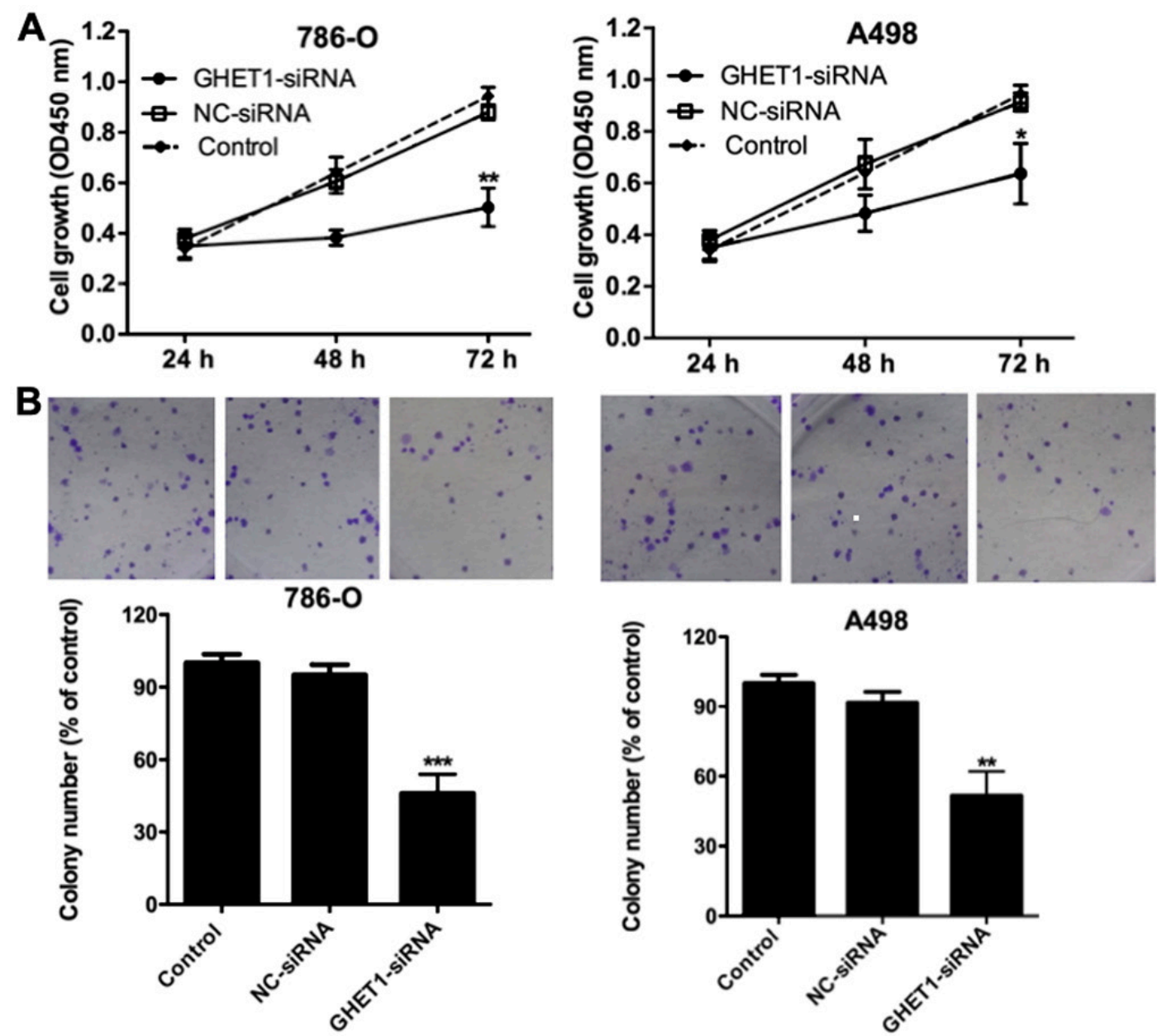

Figure 3. GHETI knockdown inhibits cell proliferation. (A) Cell Counting Kit-8 assays were performed to measure the proliferative ability of RCC cells transfected with GHETI-siRNA compared with cells transfected with NC-siRNA. (B) Colony formation assay was performed on RCC cells transfected with GHETI-siRNA or NC-siRNA (magnification, $\mathrm{x} 10$ ). ${ }^{* *} \mathrm{P}<0.01 ;{ }^{* * * *} \mathrm{P}<0.001$, vs. paired NC group.

$(\mathrm{P}<0.05$; Fig. 2A and C). Similar results were detected with regards to GHET1 protein expression ( $\mathrm{P}<0.05$; Fig. $2 \mathrm{~B}$ and $\mathrm{D})$, confirming effective siRNA silencing.

GHET1 knockdown inhibits cell proliferation and migration. The CCK-8 assay was used to detect cell proliferation. After $48 \mathrm{~h}$ GHET1-siRNA transfection, proliferation was significantly inhibited in the 786-O and A498 cell lines $(\mathrm{P}<0.05$; Fig. 3A). GHET1 silencing had a similar effect on the colony formation of $786-\mathrm{O}$ and A498 cell lines ( $\mathrm{P}<0.01$; Fig. 3B). The scratch assay demonstrated that cell migratory ability was significantly decreased in the GHET1-siRNA group compared with the NC group $(\mathrm{P}<0.01$ Fig. 4A; $(\mathrm{P}<0.05$, Fig. 4B).

GHET1 regulates epithelial-mesenchymal-transition (EMT)-associated protein expression. The EMT has been reported to serve a crucial role in cancer metastasis and expansion of the cancer stem cell population (15). In the present study, the possible effects of GHET1 on EMT were therefore assessed. Western blotting confirmed that GHET1 knockdown induced a significant increase in E-cadherin expression, whereas fibronectin and vimentin protein levels were significantly reduced $(\mathrm{P}<0.05$; Fig. $5 \mathrm{~A}$ and $\mathrm{B})$.

\section{Discussion}

Although various treatment methods are available for RCC, including surgery, chemotherapy and minor biotherapy, the prognosis of advanced or metastatic RCC remains poor. In the past 20 years, cytokine treatment has become a standard therapy for metastatic RCC. Interferon- $\alpha$, interleukin-2, sunitinib, sorafenib and bevacizumab have demonstrated favorable results in clinical trials involving patients with metastatic RCC, although the drug toxicity has not been established (16-19). A better understanding of the mechanisms underlying RCC and the identification of novel therapeutic targets are therefore a priority to develop novel metastatic RCC treatments and improve prognosis. The incidence and development of RCC being very complex, various factors, such as lncRNAs, have been considered to serve a role in RCC diagnosis and therapy.

The analysis of extensive gene expression and copy number variation of lncRNAs has demonstrated that alteration of their expression is associated with tumor development. Cao et al reported that downregulation of cancer susceptibility candidate 2 (CASC2) lncRNA by microRNA-21 increases RCC proliferation and migration, thus suggesting that CASC2 may be a tumor suppressor gene in RCC (20). In addition, 


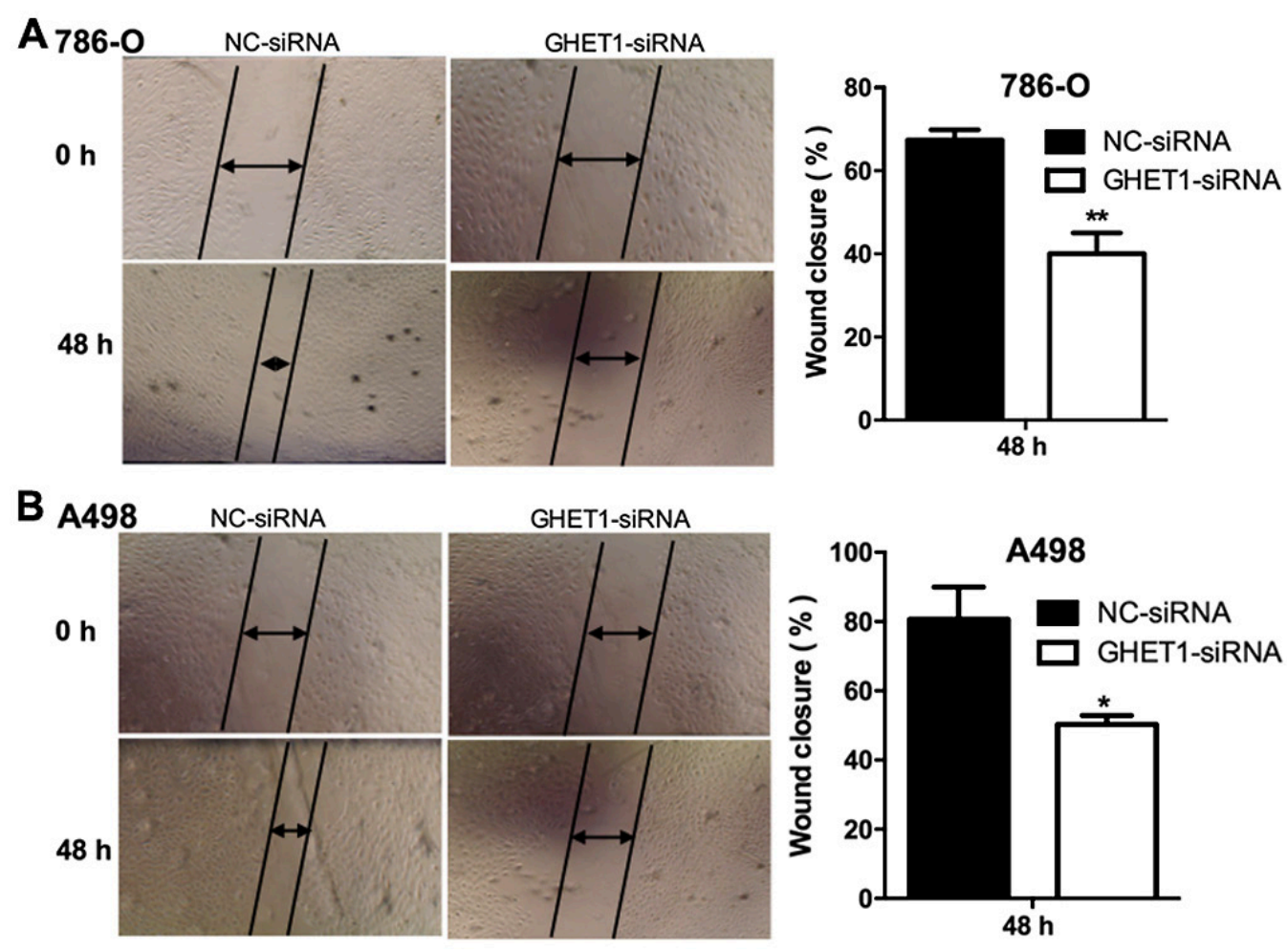

Figure 4. GHETI knockdown inhibits cell migration. (A) Cell migration scratch assay was performed on 786-O cells transfected with GHETI-siRNA or NC-siRNA. (B) Cell migration scratch assay was performed on A498 cells transfected with GHETI-siRNA or NC-siRNA. Cell images were captured by an inverted microscope (magnification, $\mathrm{x} 10$ ). ${ }^{*} \mathrm{P}<0.05,{ }^{* * *} \mathrm{P}<0.01$, vs. paired $\mathrm{NC}$ group. GHET1, gastric carcinoma proliferation enhancing transcript $1 ; \mathrm{NC}$, negative control; siRNA, small interfering RNA.
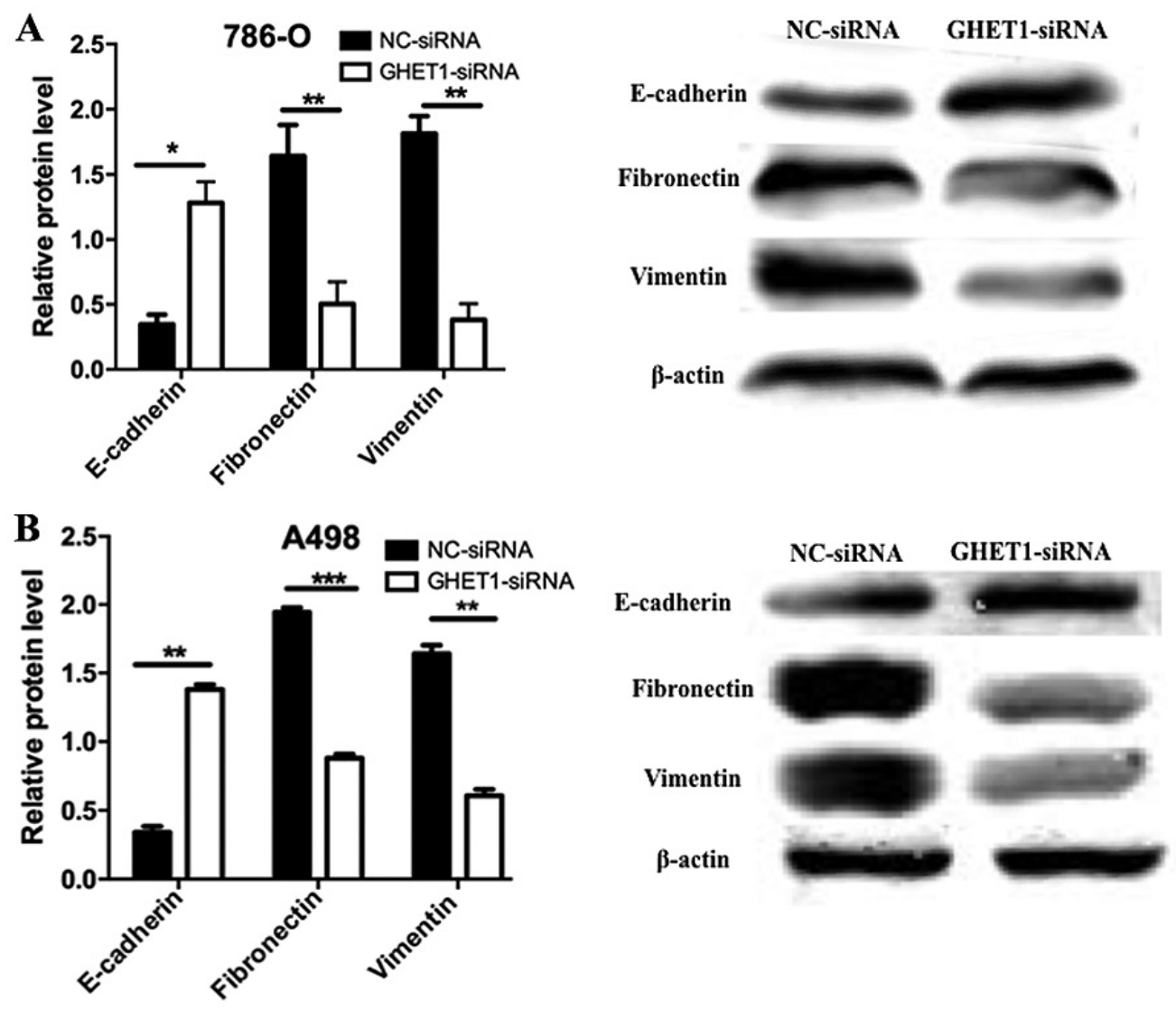

Figure 5. GHETl regulates EMT-associated expression. (A) Western blot analysis was used to detect the effects of GHETl silencing on cell epithelial markers (E-cadherin and fibronectin), and mesenchymal markers (vimentin) in 786-O cells. (B) Western blotting was used to detect the effects of GHETl silencing on cell epithelial markers (E-cadherin and fibronectin) and mesenchymal markers (vimentin) in A498 cells. ${ }^{*} \mathrm{P}<0.05,{ }^{* * *} \mathrm{P}<0.01 ;{ }^{* * * *} \mathrm{P}<0.001$, vs. paired NC group. GHET1, gastric carcinoma proliferation enhancing transcript 1; NC, negative control; siRNA, small interfering RNA. 
the suppressing androgen receptor in renal cell carcinoma (SARCC) lncRNA has been demonstrated to attenuate RCC cell invasion, migration and proliferation in vitro and in vivo via altering androgen receptor miRNA-143-3p signals; SARCC may therefore be associated with a better prognosis in patients with RCC (21). HOX transcript antisense RNA (HOTAIR) is another lncRNA involved in RCC. Its expression has been demonstrated to be increased in RCC, thus promoting cell proliferation, migration and the EMT process, and inhibiting cell apoptosis via microRNA-217/hypoxia-inducible factor 1- $\alpha /$ AXL receptor tyrosine kinase signaling (22). In addition, GHET1 has been identified as a tumor promoter and prognostic biomarker in various types of cancer, including hepatocellular carcinoma (23), pancreatic ductal adenocarcinoma (24), non-small cell lung cancer (25) and breast cancer (26).

The present study aimed to characterize the role of GHET1 in RCC. GHET1 was significantly overexpressed in RCC tissues and 786-O and A498 cell lines, compared with in adjacent normal tissues and 293 cells, respectively. Furthermore, the knockdown of GHET1 in 786-O and A498 cells significantly inhibited cell proliferation and migration. These findings suggested that downregulation of GHET1 may inhibit the development and progression of RCC.

Although EMT was originally defined in the context of developmental stages, its evolution from normal to transformed cell phenotype has been associated with carcinoma progression (27). Essential hallmarks of EMT include loss of E-cadherin, and increased vimentin and fibronectin (28). In addition, numerous transcription factors including snail, slug, zing finger E-box binding homeobox 1 and twist have been demonstrated to be involved in the EMT process (29). A previous study identified that some lncRNAs serve a role in the regulation of EMT. For example, the suppression of HOTAIR can reverse EMT in gastric cancer and reduce invasiveness, thus suggesting that HOTAIR may be a novel target in the diagnosis and treatment of gastric cancer (30). In the present study, the expression of hallmarks and transcription factors associated with EMT were examined following GHET1 silencing in RCC cells. Knockdown of GHET1 was revealed to downregulate vimentin and fibronectin expression, and to upregulate E-cadherin. These results suggested that GHET1 knockdown was associated with EMT modifications.

In conclusion, to the best of our knowledge, the present study is the first to explore the expression and biological functions of GHET1 in RCC. The results demonstrated that GHET1 was highly expressed in RCC tissues and cells, which was positively associated with the histological grade and clinical stage of cancer, and the presence of metastasis. In addition, inhibition of GHET1 expression decreased cell proliferation and migration. This inhibitory effect on tumor progression may be mediated by the EMT process, and may lead to the development of a novel diagnostic marker and therapeutic strategy for RCC.

\section{Acknowledgements}

Not applicable.

\section{Funding}

No funding was received.

\section{Availability of data and materials}

The datasets used and/or analyzed during the current study are available from the corresponding author on reasonable request.

\section{Authors' contributions}

WX, XL and MM performed RT-qPCR and western-blot assays. XY and BG performed the cells proliferation and migration experiments. JC conceptualised the study and wrote the original draft. TS and QC collected and curated the data. All authors read and approved the final manuscript.

\section{Ethics approval and consent to participate}

This study was approved by the Human Ethics Committee of The First Affiliated Hospital of Nanchang University (Nanchang, China). All patients provided written informed consent.

\section{Patient consent for publication}

Not applicable.

\section{Competing interests}

The authors declare that they have no competing interests.

\section{References}

1. Siegel RL, Miller KD and Jemal A: Cancer statistics, 2018. CA Cancer J Clin 68: 7-30, 2018.

2. Lam JS, Leppert JT, Belldegrun AS and Figlin RA: Novel approaches in the therapy of metastatic renal cell carcinoma. World J Urol 23: 202-212, 2005.

3. Janzen NK, Kim HL, Figlin RA and Belldegrun AS: Surveillance after radical or partial nephrectomy for localized renal cell carcinoma and management of recurrent disease. Urol Clin North Am 30: 843-852, 2003.

4. Kugel JF and Goodrich JA: Non-coding RNAs: Key regulators of mammalian transcription. Trends Biochem Sci 37: 144-151, 2012.

5. Fachel AA, Tahira AC, Vilella-Arias SA, Maracaja-Coutinho V, Gimba ER, Vignal GM, Campos FS, Reis EM and Verjovski-Almeida S: Expression analysis and in silico characterization of intronic long noncoding RNAs in renal cell carcinoma: Emerging functional associations. Mol Cancer 12: 140, 2013.

6. Bhan A and Mandal SS: LncRNA HOTAIR: A master regulator of chromatin dynamics and cancer. Biochim Biophys Acta 1856: 151-164, 2015.

7. Cui Y, Zhang F, Zhu C, Geng L, Tian T and Liu H: Upregulated lncRNA SNHG1 contributes to progression of non-small cell lung cancer through inhibition of miR-101-3p and activation of Wnt/B-catenin signaling pathway. Oncotarget 8: 17785-17794, 2017.

8. She K, Yan H, Huang J, Zhou H and He J: miR-193b availability is antagonized by LncRNA-SNHG7 for FAIM2-induced tumour progression in non-small cell lung cancer. Cell Prolif: $51,2018$.

9. Yang F, Xue X, Zheng L, Bi J, Zhou Y, Zhi K, Gu Y and Fang G: Long non-coding RNA GHET1 promotes gastric carcinoma cell proliferation by increasing c-Myc mRNA stability. FEBS J 281: 802-813, 2014.

10. Zhou J, Li X, Wu M, Lin C, Guo Y and Tian B: Knockdown of long noncoding RNA GHET1 inhibits cell proliferation and invasion of colorectal cancer. Oncol Res 23: 303-309, 2016. 
11. Hugo H, Ackland ML, Blick T, Lawrence MG, Clements JA Williams ED and Thompson EW: Epithelial-mesenchymal and mesenchymal-epithelial transitions in carcinoma progression. J Cell Physiol 213: 374-383, 2007.

12. Weischenfeldt J, Simon R, Feuerbach L, Schlangen K, Weichenhan D, Minner S, Wuttig D, Warnatz HJ, Stehr H, Rausch $\mathrm{T}$, et al: Integrative genomic analyses reveal an androgen-driven somatic alteration landscape in early-onset prostate cancer. Cancer Cell 23: 159-170, 2013.

13. Thiery JP, Acloque H, Huang RY and Nieto MA: Epithelial-mesenchymal transitions in development and disease. Cell 139: 871-890, 2009.

14. Livak KJ and Schmittgen TD: Analysis of relative gene expression data using real-time quantitative PCR and the 2(-Delta Delta C(T)) method. Methods 25: 402-408, 2001.

15. Abell AN and Johnson GL: Implications of mesenchymal cells in cancer stem cell populations: Relevance to EMT. Curr Pathobiol Rep 2: 21-26, 2014.

16. Thiounn N, Mathiot C, Dorval T, Flam TA, Tartour E, Mosseri V, Zerbib M, Fridman WH and Debre B: Lack of efficacy of low-dose subcutaneous recombinant interleukin-2 and interferon-alpha in the treatment of metastatic renal cell carcinoma. Br J Urol 75: 586-589, 1995.

17. Abel EJ and Wood CG: Cytoreductive nephrectomy for metastatic RCC in the era of targeted therapy. Nat Rev Urol 6: 375-383, 2009

18. Faris JE and Michaelson MD: Targeted therapies: Sunitinib versus interferon-alpha in metastatic RCC. Nat Rev Clin Oncol 7: 7-8, 2010.

19. Grünwald V, Weikert S, Seidel C, Busch J, Johannsen A, Fenner M, Reuter C, Ganser A and Johannsen M: Efficacy of sunitinib re-exposure after failure of an mTOR inhibitor in patients with metastatic RCC. Onkologie 34: 310-314, 2011.

20. Cao Y, Xu R, Xu X, Zhou Y, Cui L and He X: Downregulation of IncRNA CASC2 by microRNA-21 increases the proliferation and migration of renal cell carcinoma cells. Mol Med Rep 14: 1019-1025, 2016.

21. Zhai W, Sun Y, Guo C, Hu G, Wang M, Zheng J, Lin W, Huang Q, Li G, Zheng J and Chang C: LncRNA-SARCC suppresses renal cell carcinoma (RCC) progression via altering the androgen receptor(AR)/miRNA-143-3p signals. Cell Death Differ 24 1502-1517, 2017.
22. Hong Q, Li O, Zheng W, Xiao WZ, Zhang L, Wu D, Cai GY, He JC and Chen XM: LncRNA HOTAIR regulates HIF-1 $\alpha / A X L$ signaling through inhibition of miR-217 in renal cell carcinoma. Cell Death Dis 8: e2772, 2017.

23. Jin L, He Y, Tang S and Huang S: LncRNA GHET1 predicts poor prognosis in hepatocellular carcinoma and promotes cell proliferation by silencing KLF2. J Cell Physiol 233: 4726-4734, 2018.

24. Zhou HY, Zhu H, Wu XY, Chen XD, Qiao ZG, Ling X, Yao XM and Tang JH: Expression and clinical significance of long-non-coding RNA GHET1 in pancreatic cancer. Eur Rev Med Pharmacol Sci 21: 5081-5088, 2017.

25. Guan ZB, Cao YS, Li Y, Tong WN and Zhuo AS: Knockdown of lncRNA GHET1 suppresses cell proliferation, invasion and LATS1/YAP pathway in non small cell lung cancer. Cancer Biomark 21: 557-563, 2018.

26. Song R, Zhang J, Huang J and Hai T: Long non-coding RNA GHET1 promotes human breast cancer cell proliferation, invasion and migration via affecting epithelial mesenchymal transition. Cancer Biomark 22: 565-573, 2018.

27. Savagner P: The epithelial-mesenchymal transition (EMT) phenomenon. Ann Oncol 21 (Suppl 7): vii89-vii92, 2010.

28. Tam WL and Weinberg RA: The epigenetics of epithelial-mesenchymal plasticity in cancer. Nat Med 19: 1438-1449, 2013.

29. Djebali S, Davis CA, Merkel A, Dobin A, Lassmann T, Mortazavi A, Tanzer A, Lagarde J, Lin W, Schlesinger F, et al: Landscape of transcription in human cells. Nature 489: 101-108, 2012.

30. Xu ZY, Yu QM, Du YA, Yang LT, Dong RZ, Huang L, Yu PF and Cheng XD: Knockdown of long Non-coding RNA HOTAIR suppresses tumor invasion and reverses Epithelial-mesenchymal transition in gastric cancer. Int J Biol Sci 9: 587-597, 2013.

This work is licensed under a Creative Commons Attribution-NonCommercial-NoDerivatives 4.0 International (CC BY-NC-ND 4.0) License. 